\title{
PRECIOS PREDATORIOS: UNA REVISIÓN TEÓRICA Y EVIDENCIA EXPERIMENTAL
}

\section{Oscar Jorge Molina Tejerina}

\section{RESUMEN}

El presente trabajo presenta un resumen de lo hecho en materia de entender, poner a prueba y modelar la existencia de comportamiento estratégico en las firmas, cuando enfrentan a otras que pueden arrebatarle mercado en un contexto en el cual se tiene información limitada sobre las características de los participantes en este juego. Fundamentalmente, en la parte teórica se analizan dos modelos que llegan a conclusiones distintas. Asimismo, se analiza lo que se hizo empíricamente en el tema, se discute brevemente un trabajo experimental a fin de ver si la teoría se cumple en un ambiente "controlado" y, finalmente, se discute el procedimiento y los resultados obtenidos en dos experimentos económicos sobre precios predatorios llevados a cabo para este trabajo, uno en la Universidad de Chile y otro en la Universidad Privada Boliviana. El trabajo discute principalmente el tema de los precios límite y los precios predatorios, encontrando que existe evidencia de comportamiento predatorio, así como prácticas colusivas y de acomodación.

Palabras Clave: Precios Predatorios, Precios Límite, Prácticas Colusivas, Prácticas de Acomodación. 